\title{
Long-term outcomes of a Malone antegrade continence enema (MACE) for the treatment of fecal incontinence or constipation in adults
}

Citation for published version (APA):

Sturkenboom, R., van der Wilt, A. A., van Kuijk, S. M. J., Ahmad, A., Janssen, P. T., Stassen, L. P. S., Melenhorst, J., \& Breukink, S. O. (2018). Long-term outcomes of a Malone antegrade continence enema (MACE) for the treatment of fecal incontinence or constipation in adults. International Journal of Colorectal Disease, 33(10), 1341-1348. https://doi.org/10.1007/s00384-018-3088-5

Document status and date:

Published: 01/10/2018

DOI:

10.1007/s00384-018-3088-5

Document Version:

Publisher's PDF, also known as Version of record

Document license:

Taverne

Please check the document version of this publication:

- A submitted manuscript is the version of the article upon submission and before peer-review. There can be important differences between the submitted version and the official published version of record.

People interested in the research are advised to contact the author for the final version of the publication, or visit the DOI to the publisher's website.

- The final author version and the galley proof are versions of the publication after peer review.

- The final published version features the final layout of the paper including the volume, issue and page numbers.

Link to publication

\footnotetext{
General rights rights.

- You may freely distribute the URL identifying the publication in the public portal. please follow below link for the End User Agreement:

www.umlib.nl/taverne-license

Take down policy

If you believe that this document breaches copyright please contact us at:

repository@maastrichtuniversity.nl

providing details and we will investigate your claim.
}

Copyright and moral rights for the publications made accessible in the public portal are retained by the authors and/or other copyright owners and it is a condition of accessing publications that users recognise and abide by the legal requirements associated with these

- Users may download and print one copy of any publication from the public portal for the purpose of private study or research.

- You may not further distribute the material or use it for any profit-making activity or commercial gain

If the publication is distributed under the terms of Article $25 \mathrm{fa}$ of the Dutch Copyright Act, indicated by the "Taverne" license above, 


\title{
Long-term outcomes of a Malone antegrade continence enema (MACE) for the treatment of fecal incontinence or constipation in adults
}

\author{
R. Sturkenboom ${ }^{1}$ - A. A. van der Wilt ${ }^{1}$ - S. M. J. van Kuijk ${ }^{2}$ - A. Ahmad ${ }^{1}$ • P. T. Janssen ${ }^{1}$ • L. P. S. Stassen ${ }^{1}$ \\ J. Melenhorst ${ }^{1} \cdot$ S. O. Breukink ${ }^{1}$
}

Accepted: 15 May 2018 / Published online: 22 June 2018

(C) Springer-Verlag GmbH Germany, part of Springer Nature 2018

\begin{abstract}
Purpose The aim of the study was to assess the long-term outcome of a Malone antegrade continence enema (MACE) procedure for fecal incontinence or constipation in adults.

Methods This retrospective single-center study assessed the long-term outcome and quality of life (QoL) of patients who underwent a MACE procedure between 2005 and 2014 at the Maastricht University Medical Centre. Success rate was quantified by using Malone's continence scale. Quality of life was assessed by validated questionnaires covering general quality of life (SF36 and Karnofsky scale), current pain level (visual analog scale), fecal incontinence (Vaizey incontinence survey), or constipation (Cleveland Clinic Constipation Score).

Results Based on patients' records, 22 out of 30 patients (73\%; 95\% CI 54-87\%) were still using their MACE. Mean follow-up was 43 months (SD 25.9) since time of surgery. According to the Malone continence scale, the overall success rate was $37 \%$ (95\% CI 20.0-53.3). Nine patients developed a postoperative complication. Eighteen out of 22 patients (13 with constipation and 5 with fecal incontinence) returned the QoL questionnaires (82\% response rate). Long-term quality of life of patients with a MACE did not differ from the general Dutch population.

Conclusions In our cohort of patients with fecal incontinence or constipation, MACE resulted in a disappointed overall success rate of $37 \%$. However, it may be indicated in patients who do not prefer more invasive surgical procedures or a definite stoma. The success and morbidity rate should be thoroughly discussed with the patients preoperatively.
\end{abstract}

Keywords Constipation $\cdot$ Fecal incontinence $\cdot$ Malone antegrade continence enema $\cdot$ Quality of life

\section{Introduction}

Idiopathic fecal incontinence and functional constipation impose a considerable burden on patients. Fecal incontinence is highly prevalent, ranging from 2.2 to $15 \%$ in the general population and up to $40 \%$ in nursing homes [1-3]. The treatment of fecal incontinence and constipation starts with conservative treatment like bulk agents, retrograde washouts, and pelvic

R. Sturkenboom

roselst@hotmail.com

1 Department of Surgery, Maastricht University Medical Centre, PO Box 5800, 6202 AZ Maastricht, The Netherlands

2 Department of Clinical Epidemiology and Medical Technology Assessment, Maastricht University Medical Centre, Maastricht, The Netherlands floor therapy [4]. Sacral neuromodulation can be considered if conservative treatment in patients with fecal incontinence fails [4]. The next step after conservative treatment in constipated patients is often a stoma or a subtotal colectomy. This is a major, invasive, and irreversible procedure, which is associated with high morbidity, frequent adverse events, and highly variable outcome [5-7]. If the patient prefers to eschew such invasive procedures, a Malone stoma can be considered for antegrade colon irrigation. The Malone antegrade continence enema (MACE) was first described in 1990 by Malone et al. [8]. They specified a new operative technique enabling antegrade washouts to accomplish production of stool. During this procedure, the appendix is attached to the anterior abdominal wall to serve as a continent stoma. If the appendix has been removed before, the procedure consists of a neoappendicostomy by using a segment of the terminal ileum or a cecal flap [9]. The MACE was first introduced in patients with fecal incontinence to become pseudo continent [10-12]. 
Later studies demonstrated that the MACE could also be effective in patients who suffer from constipation [13-16].

The current literature is mainly focused on the success rate in children. In the adult population, data of long-term outcome and quality of life of the MACE show contradictory results [12, 17-19]. The median follow-up of these studies ranges between 6 and 75 months, covering cohorts of 5-80 patients. The aim of this study is to report long-term outcome and quality of life of eighteen adult patients with fecal incontinence or constipation treated with MACE.

\section{Methods}

This is a retrospective observational study in which we retrieved patient characteristics from hospital records and sent postal questionnaires to ascertain current functional outcome. All patients suffering from fecal incontinence or constipation who underwent a MACE procedure at Maastricht University Medical Centre between 1997 and 2014 were selected. Medical charts of these patients were reviewed and data regarding indication, history, previous surgery for fecal incontinence or constipation, surgical procedure, and peri- and post-operative complications and revisions were extracted. All patients who, according to their medical records, were still using MACE were contacted by mail to participate in the study. In case of no response, patients were reminded by telephone within 2 weeks.

\section{Surgical procedure}

The MACE procedure is an operative technique to facilitate the administration of antegrade washouts to empty the colon by using the (neo-)appendix. The appendix is brought out to the abdominal wall in a non-refluxing manner as a continent stoma [8]. If the appendix was still in situ and suitable for fixation to the abdominal wall, a classical appendicostomy was performed. In all other cases, a neoappendicostomy was performed where a cecal flap was used to staple to the abdominal wall [9]. The procedure was performed both by laparotomy or laparoscopy. Antibiotics, cefazolin (INN), and metronidazole were administered to all patients preoperatively.

\section{Success rate}

To evaluate the efficacy of the MACE procedure, Malone introduced a continence scale which was based on several criteria categorizing the success rate as full, partial, or failure [17]. Full success represents totally clean or minor rectal leakage on the night of the washout. Partial success represents clean but significant stomal or rectal leakage, occasional major leaks, still wearing protection, and perceived improvement by the parents or child. Failure represents regular soiling or constipation, no perceived improvement, or the procedure abandoned. According to the Malone continence scale, the overall success rate was calculated by combining the full and partial success rates, using the number of patients in the intention-to-treat group as denominator $(n=30)$ [18].

\section{Questionnaires}

General quality of life was assessed using the SF-36 [19-22]. The raw scores of the eight different domains were linearly transformed to scores ranging from 0 to 100; a higher score indicates a better health status.

To assess the level of a patient's general well-being and activities in daily life, the Karnofsky Performance Status was used [23, 24]. This score is mostly used in patients with cancer and indicates the level of requirement of medical care on a scale from 0 to 100 . Scores of $100,70,40$, and 0 correspond with "no complaints, no evidence of disease," "cares for self, unable to carry out normal activity or to do active work," "disabled, requiring special care and assistance," and "dead," respectively.

The visual analog scale (VAS) provides information regarding the minimum and maximum levels of pain currently experienced by the patients. The score ranged from 0 to 10 ; a score of 0 corresponds with no pain, and scores of $1-3,4-6$, and 7-10 correspond to mild, moderate, and severe pain, respectively [28-30].

The Vaizey survey was used in patients who suffered from fecal incontinence. Incontinence was scored from 0 to 24 and major incontinence was defined as a score of 7 or higher. Patients are asked to report on frequency of incontinence and alterations in life style, the need to wear pads or plugs, constipating medication, and the lack of ability to defer defecation for $15 \mathrm{~min}$. The Vaizey survey has been validated for Dutch language [25-27].

Constipation was assessed using the Cleveland Clinic Constipation Score [25]. With this questionnaire, patients are asked to report on the frequency of bowel movements, of painful, incomplete, and unsuccessful evacuation, of abdominal pain, time spent in lavatory and need for assistance, and duration of constipation. A score above 15 was considered as constipation.

\section{Complication score}

Complications were graded according to the Clavien-Dindo classification [28]. Minor complications are classified as grade I (deviation from normal postoperative course, not requiring intervention) or II (requiring pharmacological intervention) and major complications as grade III (requiring surgical, endoscopic, or radiological intervention) and IV (life threatening). A fatal adverse event is classified as grade $\mathrm{V}$. 


\section{Statistics}

Patient characteristics are presented as mean (standard deviation [SD]), median (interquartile range [IQR]), or absolute number (\%), as appropriate. Homogeneity of variances was assessed using Levene's test. The outcome of the SF-36 was compared to the reference values of the general population [22]. This was analyzed using a two-tailed unpaired $t$ test. A $p$ value of $<0.05$ was considered statistically significant.

All analyses were performed using IBM SPSS version 20 (SPSS, Chicago, IL) and these analyses were performed in May of 2015.

\section{Results}

\section{Demographics}

A flow chart of the process of inclusion is shown in Fig. 1. Thirty patients underwent a MACE procedure in the Maastricht University Medical Centre between 1997 and 2014. During the follow-up period, the MACE stoma was removed in $8(26.7 \%)$ patients. Reasons for removal were lack of efficacy $(n=3)$, stoma leakage $(n=2)$, washouts were not feasible because of the worsened stage of multiple sclerosis $(n=1)$, and in two patients, the cause of failure was unknown. Six of these eight patients underwent a colostomy. One patient underwent an ileocecal resection, followed by a split ileo-/ ascendostomy, and in another patient, a subtotal colectomy with ileorectal anastomosis was performed. In total, 22 patients $(73.3 \%)$ were still using the MACE after a maximum

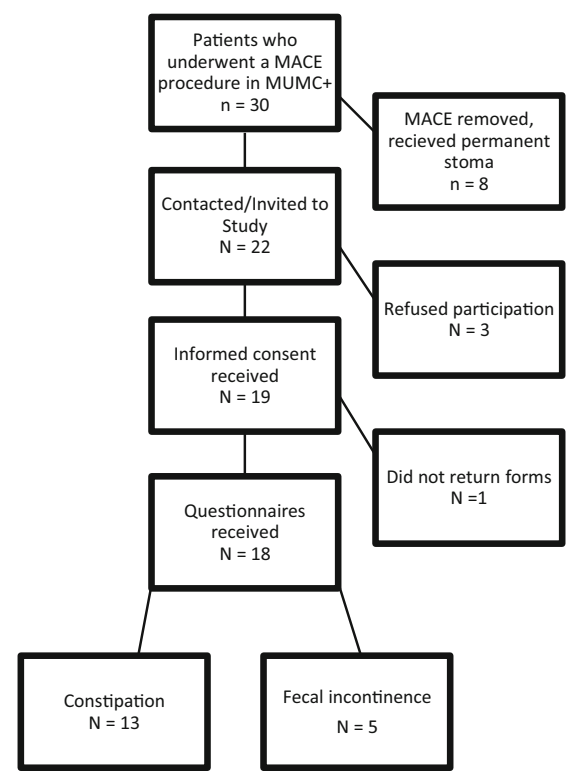

Fig. 1 Flow chart of patient inclusion follow-up of 8.4 years. These patients were eligible for this study and 18 patients completed the questionnaires, resulting in a response rate of $81.8 \%$. Thirteen patients had constipation and $5(27.8 \%)$ had fecal incontinence. The characteristics of the 18 responders are described in Table 1. The etiology of the different causes of fecal incontinence and constipation is displayed in Table 2.

All patients underwent a prolonged period of failed conservative bowel management before the MACE procedure. The mean symptom duration before MACE was 10.9 years (SD 7.4). To treat constipation, patients used laxatives $(n=12)$, retrograde enemas $(n=13)$, and rectal suppositories $(n=7)$. To treat fecal incontinence, two patients used pelvic floor therapy and two used retrograde enemas. Twelve patients $(66.7 \%)$ underwent previous surgery to treat the underlying cause of the fecal incontinence/constipation: sacral nerve stimulation $(n=9)$, rectovaginopexy $(n=2)$, recto-uteropexy $(n=$ $1)$, and rectumextirpation with colo-anal anastomosis because of a malignancy $(n=1)$.

\section{Surgical technique}

Surgical procedure was open in $11(61.1 \%)$ and laparoscopic in $7(38.9 \%)$ patients. In 12 patients, an appendicostomy was performed, and in 6, a neoappendicostomy. Data regarding the MACE are shown in Table 4.

\section{MACE usage}

All patients used tap water to perform the antegrade washouts. The median duration of each washout was $38.5 \mathrm{~min}$ (range 15-60). The amount of fluid used ranged from 150 to $2000 \mathrm{~cm}^{3}$ (median 1500) for each antegrade continence enema administration. Thirteen $(72.2 \%)$ patients performed washouts daily, one patient twice a day, one patient five times a week, and three patients less than five times a week. Most patients $(n=13)$ performed the washouts themselves. The washouts in the other patients were performed by parents $(n=3)$, caregivers $(n=1)$, or partner $(n=1)$.

Nine patients $(50 \%)$ reported leakage during antegrade washouts. Eight patients suffered from (some) pain during antegrade washouts. Soiling was reported by six of the patients ranging from once a day (2), twice a week (1), once a week (2), up to once a month (1).

Thirteen patients needed supplementary treatment to facilitate antegrade washouts: ten patients used laxatives, one patient used bulking agents, and two patients used spasmolytics.

\section{Overall success rate}

Using the Malone criteria, the procedure was successful in 11 of the intention-to-treat cohort $(N=30)(36.7 \%$; $95 \%$ CI 20.0 
Table 1 Patient characteristics

\begin{tabular}{lll}
\hline & Constipation $n=13$ & Fecal incontinence $n=5$ \\
\hline Female sex $(n)$ & 11 & 4 \\
Mean age (SD) & $39(18.1$ years $)$ & 48 (19.9 years) \\
Mean age at surgery (SD) & $35(19.3$ years $)$ & 46 (19.7 years) \\
Mean follow-up duration (SD) & $50.2(26.4$ months $)$ & 23.1 (9.1 months) \\
Mean symptom duration before appendicostomy (SD) & $10.7(7.6$ years $)$ & 11.4 (7.6 years) \\
Median BMI $\left(\mathrm{kg} / \mathrm{m}^{2}\right)(\mathrm{SD})$ & $23.5(6.3)$ & $25.8(5.9)$ \\
Comorbidities $(n)$ & & 1 \\
- None & 3 & 3 \\
- Cardiovascular & 2 & 0 \\
- Respiratory & 2 & 0 \\
- Neurologic & 3 & 0 \\
- Inflammatory & 1 & 1 \\
- Urologic & 2 & 2 \\
Smoking status $(n)$ & & 1 \\
- Never smoked & 8 & 2 \\
- Smoked in the past & 2 & \\
- Current smoker & 3 &
\end{tabular}

53.3). Full and partial success was reached in 4 and 7 patients $(13 \%, 95 \%$ CI $4-32$ and $23 \%, 95 \%$ CI 11-43), respectively.

\section{Success rate in patients with fecal incontinence $(n=5)$}

According to the Vaizey score and the presence of rectal or stomal leakage, none of the five patients with fecal incontinence reached full success, three reached partial success, and in two patients, the MACE failed.

\section{Success rate in patients with constipation $(n=13)$}

According to the Cleveland Clinic Constipation Score, of the 13 included patients with constipation, 4 patients reached full success, 4 reached partial success and in 5 patients, the MACE failed due to regular constipation (score $>15$ ).

\section{Quality of life, general well-being, and pain}

Results of the SF-36 questionnaire and of the Dutch general population are presented in Table 3. Patients who underwent a MACE procedure scored substantially lower on all SF-36 domains compared to a Dutch reference population, although none of these differences were statistically significant when taking multiple comparisons into account.

The mean Karnofsky score was 63.1 (SD 13.2) in the fecal incontinence group, indicating that patients were usually unable to carry out normal activities, but able to care for themselves.
Table 2 Etiology of fecal incontinence and constipation in 18 patients

\begin{tabular}{ll}
\hline Etiology & Number of patients \\
\hline Spina bifida & 4 \\
Spinal cord lesion (including paraplegia, caudal equine lesion, spinal cord injury) & 3 \\
Rectocele & 3 \\
Idiopathic slow-transit constipation & 2 \\
Psychological & 2 \\
Diabetic neuropathy & 1 \\
Multiple sclerosis & 1 \\
Neoplasm (rectum) & 1 \\
Primary IgA immunodeficiency & 1 \\
\hline
\end{tabular}


Table 3 Results of the SF-36 and norm-based scores

\begin{tabular}{llll}
\hline Subscale & MACE & General population & $p$ value \\
\hline Physical functioning & $35.6(35.2)$ & $83.0(22.8)$ & 0.15 \\
Role physical & $43.1(45.2)$ & $76.4(36.3)$ & 0.38 \\
Bodily pain & $49.8(27.2)$ & $74.9(23.4)$ & 0.29 \\
General health & $60.3(9.3)$ & $70.7(20.7)$ & 0.47 \\
Vitality & $50.3(12.1)$ & $68.6(19.3)$ & 0.24 \\
Social functioning & $45.1(9.7)$ & $84.0(22.4)$ & 0.051 \\
Role emotional & $87.0(32.6)$ & $82.3(32.9)$ & 0.87 \\
Mental health & $64.7(6.2)$ & $76.8(17.4)$ & 0.32 \\
\hline
\end{tabular}

Values as mean (SD)

The mean minimal pain level was 3.5 (SD 2.6) and the mean maximum level was 7.6 (SD 2.0) in patients with fecal incontinence, indicating moderate to severe pain.

In patients with constipation, the mean Karnofsky score was 68.0 (SD 16.4), indicating that patients were usually unable to carry out normal activities, but able to care for themselves. Mean minimum and maximum pain levels in these patients were 2.3 (SD 1.5) to 6.2 (SD 1.8), respectively, indicating mild to moderate pain.

\section{Complications}

Postoperative complications were observed in all 5 patients with fecal incontinence and in 4 of the 13 patients (30.8\%) with constipation. These complications are described in Table 4 . Nine patients $(50 \%)$ had one or more complications, with three patients having multiple complications. Six patients developed an infection, classified as a minor complication according to the Clavien-Dindo classification, which was treated with antibiotics. Six patients developed major complications such as washout leakage $(n=2)$, stomal stenosis $(n=2)$, and an abscess $(n=2)$. To treat the abscess, incision

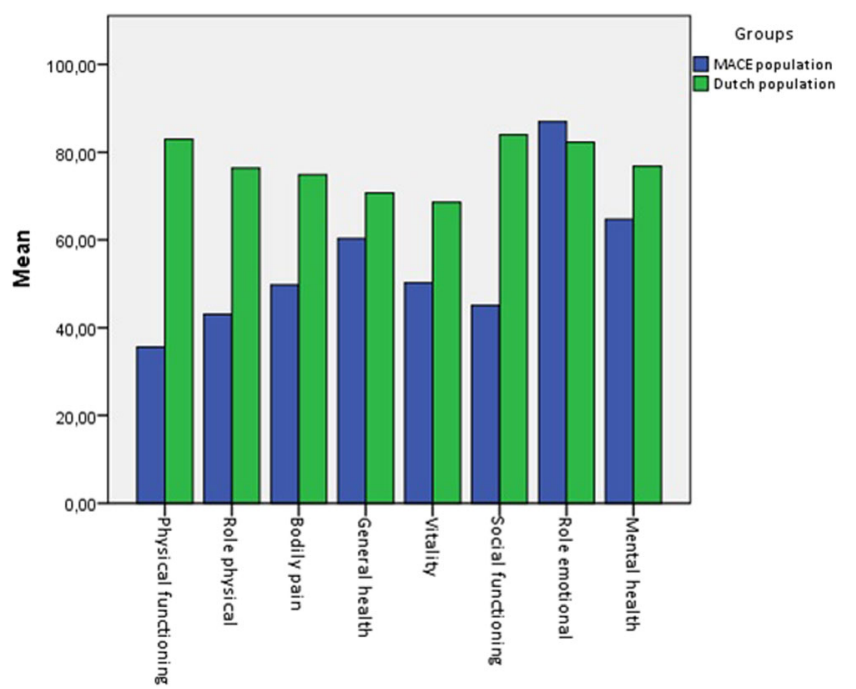

Fig. 2 Chart of the norm-based scores of the Short Form-36 questionnaires of the MACE population after surgery versus the quality of life of the Dutch population

and drainage was performed and antibiotics were prescribed. Surgical revision of the MACE was necessary in two patients $(11.1 \%)$ suffering from stenosis or leakage. In these cases, the MIC-KEY button was replaced.

\section{Discussion}

This study assessed the long-term outcome and QoL of adults who underwent a MACE procedure for the treatment of fecal incontinence or constipation. Using the Malone continence scale, we report an overall success rate of $36.7 \%$. Six patients developed major complications and two patients needed surgical revision of the MACE. Quality of life of the patients with a MACE tended to be lower than in the general Dutch population, especially in the domains of physical and social
Table 4 The surgical procedure and postoperative complications

\begin{tabular}{lll}
\hline & Constipation $n=13$ & Fecal incontinence $n=5$ \\
\hline Surgical type $(n)$ & & \\
- Laparoscopic & 6 & 1 \\
- Open & 7 & 4 \\
Surgical technique $(n)$ & & \\
- Appendicostomy & 9 & 3 \\
- Neoappendicostomy & 4 & 2 \\
Complication after surgery $(n)$ & $4(30.8 \%)$ & $5(100 \%)$ \\
- Clavien-Dindo grade I & 0 & 0 \\
- Clavien-Dindo grade II & 2 & 4 \\
- Clavien-Dindo grade III & 2 & 1 \\
- Clavien-Dindo grade IV & 0 & 0 \\
- Clavien-Dindo grade V (death) & 0 & 0 \\
\hline
\end{tabular}


functioning and bodily pain, although these differences failed to reach conventional levels of statistical significance (Fig. 2).

Relatively few studies have reported long-term outcome after the MACE procedure in adults. Most of the studies used no validated criteria defining the success rate of the procedure. Many studies used the continued use of the MACE for their primary outcome and as definition of success during followup. The majority of studies did not use validated questionnaires to assess QoL post treatment.

These inconsistencies in definitions of "successful use of the MACE" make it difficult to compare the different studies reporting on the outcome of the MACE procedure. This lack of consistency is also described in the recent published meta-analysis of Chan and Delicata [29]. They reported on the outcome of seventeen studies of MACE procedure in adults. They described a pooled success rate of $71.8 \%$. This success rate was determined by continued use of the MACE at the end of follow-up or resolution of the symptoms. This rate is similar to our study, with $73 \%$ of the patients still using the MACE.

However, if you chose to use the Malone continence scale as primary endpoint, the success rates of the previous performed studies might be lower. Using this primary endpoint, we found an overall success rate of $36.7 \%$ in our study. To our knowledge, our study used the Malone success rate for the first time in adult patients. We think that the Malone continence scale reflects more the clinical relevant success rate of the MACE than the previous mentioned outcome "continued used of the MACE at the end of follow-up or resolution of the symptoms."

Two studies in children used also the Malone success rate as primary endpoint $[10,30]$. In one study, with 21 patients with a spina bifida, the success rate was $90 \%$ with a median follow-up of 75 months. The other study included 40 children, suffering from constipation with all different etiologies, and reported a success rate of $92 \%$ with a mean follow-up of 6.5 years.

Studies publishing about quality of life after a MACE in adults and using validated questionnaires are scarce. This topic is described more comprehensively in children $[16,31,32]$. Only three studies assessed the quality of life after MACE in adults using the SF-36 [12, 33, 34]. These three studies reported the outcome of fecal incontinent patients and showed a good postoperative physical recovery and general health.

Our data suggest that at long-term follow-up, patients with a MACE struggle especially with physical and social functioning. This may be related to complications that can arise in the long run. The most common complications are the formation of granulation tissue, stomal infection, and leakage from the appendicostomy [13]. In some cases, the complications are so debilitating that patients prefer the MACE to be removed. Eight patients in our study chose to have the MACE removed for a lack of effectiveness or because of complications (stoma leakage, pain). This is in agreement with the results of Yardley et al. [35]. Revision surgeries are often necessary in these patients to resolve the complications [15, 35].

Some limitations of our study have to be addressed. First of all, this is a retrospective study and preoperative values were not available. Besides we included a heterogeneous cohort of patients suffering from fecal incontinence or constipation with different etiology. The underlying diseases may interfere with the general health of the patient. This may have affected not only the results of the SF-36, but also the visual analog scale and the Karnofsky score.

MACE was developed to offer patients the prospect of resolving the problems associated with fecal incontinence or constipation, while avoiding more invasive surgery. Our results, adopting a more realistic definition of successful outcome and including considerations such as quality of life, general well-being, and pain, show that in the long run, the results are disappointing. This underscores, once more, the utmost importance of carefully informing patients and making sure that they hold realistic expectations of the various options.

\section{Conclusions}

MACE was developed to offer patients the prospect of resolving the problems associated with fecal incontinence or constipation, while avoiding more invasive surgery. Our results, using the Malone success rate as primary endpoint, are disappointing. However, it may be indicated in patients who do not prefer more invasive surgical procedures or a definite stoma. The success and morbidity rate should be thoroughly discussed with the patients preoperatively.

Author contributions R. Sturkenboom, M.D., primary investigator, design of study, analysis and interpretation of data, acquisition of data, writing and revising of article, final approval of article. A. A. van der Wilt, M.D., design of the study, writing and revising of article, final approval of article. S. M. J. van Kuijk, Ph.D., analysis and interpretation of data, revising of article, final approval of article. A. Ahmad, M.D., acquisition of data, design of study, revising of article, final approval of article. P. T. Janssen, M.D., Ph.D., design of the study, revising of article, final approval of article. L. P. S. Stassen, M.D., Ph.D., Prof., design of the study, revising of article, final approval of article. J. Melenhorst, M.D., Ph.D., design of the study, revising of article, final approval of article. S. O. Breukink, M.D., Ph.D., corresponding author, primary investigator, design of study, analysis and interpretation of data, acquisition of data, writing and revising of article, final approval of article.

\section{Compliance with ethical standards}

Conflict of interest The authors declare that they have no conflict of interest. 
Ethical approval All procedures performed in studies involving human participants were in accordance with the ethical standards of the institutional and/or national research committee and with the 1964 Helsinki declaration and its later amendments or comparable ethical standards. This article does not contain any studies with animals performed by any of the authors.

Informed consent Informed consent was obtained from all individual participants included in the study.

\section{References}

1. Bharucha AE, Wald A, Enck P, Rao S (2006) Functional anorectal disorders. Gastroenterology 130(5):1510-1518. https://doi.org/10. 1053/j.gastro.2005.11.064

2. Longstreth GF, Thompson WG, Chey WD, Houghton LA, Mearin F, Spiller RC (2006) Functional bowel disorders. Gastroenterology 130(5):1480-1491. https://doi.org/10.1053/j.gastro.2005.11.061

3. Nelson RL (2004) Epidemiology of fecal incontinence. Gastroenterology 126(1 Suppl 1):S3-S7

4. Wexner SD, Bleier J (2015) Current surgical strategies to treat fecal incontinence. Expert Rev Gastroenterol Hepatol: 1-13. https://doi. org/10.1586/17474124.2015.1093417

5. Basilisco G, Coletta M (2013) Chronic constipation: a critical review. Digestive and Liver Disease : official journal of the Italian Society of Gastroenterology and the Italian Association for the Study of the Liver 45(11):886-893. https://doi.org/10.1016/j.dld. 2013.03.016

6. Thomas GP, Dudding TC, Rahbour G, Nicholls RJ, Vaizey CJ (2013) Sacral nerve stimulation for constipation. Br J Surg 100(2):174-181. https://doi.org/10.1002/bjs.8944

7. Knowles CH, Dinning PG, Pescatori M, Rintala R, Rosen H (2009) Surgical management of constipation. Neurogastroenterology and motility: the official journal of the European Gastrointestinal Motility Society 21(Suppl 2):62-71. https://doi.org/10.1111/j. 1365-2982.2009.01405.x

8. Malone PS, Ransley PG, Kiely EM (1990) Preliminary report: the antegrade continence enema. Lancet 336(8725):1217-1218

9. Kiely EM, Ade-Ajayi N, Wheeler RA (1994) Caecal flap conduit for antegrade continence enemas. Br J Surg 81(8):1215

10. Imai K, Shiroyanagi Y, Kim WJ, Ichiroku T, Yamazaki Y (2014) Satisfaction after the Malone antegrade continence enema procedure in patients with spina bifida. Spinal Cord 52(1):54-57. https:// doi.org/10.1038/sc.2013.111

11. Teichman JM, Zabihi N, Kraus SR, Harris JM, Barber DB (2003) Long-term results for Malone antegrade continence enema for adults with neurogenic bowel disease. Urology 61(3):502-506

12. Lefevre JH, Parc Y, Giraudo G, Bell S, Parc R, Tiret E (2006) Outcome of antegrade continence enema procedures for faecal incontinence in adults. Br J Surg 93(10):12651269. https://doi.org/10.1002/bjs.5383

13. King SK, Sutcliffe JR, Southwell BR, Chait PG, Hutson JM (2005) The antegrade continence enema successfully treats idiopathic slow-transit constipation. J Pediatr Surg 40(12):1935-1940. https://doi.org/10.1016/j.jpedsurg.2005.08.011

14. Rongen MJ, van der Hoop AG, Baeten CG (2001) Cecal access for antegrade colon enemas in medically refractory slow-transit constipation: a prospective study. Dis Colon Rectum 44(11):1644-1649

15. Meurette G, Lehur PA, Coron E, Regenet N (2010) Long-term results of Malone's procedure with antegrade irrigation for severe chronic constipation. Gastroenterol Clin Biol 34(3):209-212. https://doi.org/10.1016/j.gcb.2009.12.009
16. Har AF, Rescorla FJ, Croffie JM (2013) Quality of life in pediatric patients with unremitting constipation pre and post Malone antegrade continence enema (MACE) procedure. J Pediatr Surg 48(8):1733-1737. https://doi.org/10.1016/j.jpedsurg.2013.01.045

17. Curry JI, Osborne A, Malone PS (1998) How to achieve a successful Malone antegrade continence enema. J Pediatr Surg 33(1):138141

18. Curry JI, Osborne A, Malone PS (1999) The MACE procedure: experience in the United Kingdom. J Pediatr Surg 34(2):338-340

19. CA MH, Ware JE Jr, Lu JF, Sherbourne CD (1994) The MOS 36item Short-Form Health Survey (SF-36): III. Tests of data quality, scaling assumptions, and reliability across diverse patient groups. Med Care 32(1):40-66

20. Ware JE Jr, Sherbourne CD (1992) The MOS 36-item short-form health survey (SF-36). I. Conceptual framework and item selection. Med Care 30(6):473-483

21. McHorney CA, Ware JE Jr, Raczek AE (1993) The MOS 36-Item Short-Form Health Survey (SF-36): II. Psychometric and clinical tests of validity in measuring physical and mental health constructs. Med Care 31(3):247-263

22. Aaronson NK, Muller M, Cohen PD, Essink-Bot ML, Fekkes M, Sanderman R, Sprangers MA, te Velde A, Verrips E (1998) Translation, validation, and norming of the Dutch language version of the SF-36 Health Survey in community and chronic disease populations. J Clin Epidemiol 51(11):1055-1068

23. Schag CC, Heinrich RL, Ganz PA (1984) Karnofsky performance status revisited: reliability, validity, and guidelines. Journal of Clinical Oncology : official journal of the American Society of Clinical Oncology 2(3):187-193

24. Yates JW, Chalmer B, McKegney FP (1980) Evaluation of patients with advanced cancer using the Karnofsky performance status. Cancer 45(8):2220-2224

25. Agachan F, Chen T, Pfeifer J, Reissman P, Wexner SD (1996) A constipation scoring system to simplify evaluation and management of constipated patients. Dis Colon Rectum 39(6):681-685

26. Kamm MA, Dudding TC, Melenhorst J, Jarrett M, Wang Z, Buntzen S, Johansson C, Laurberg S, Rosen H, Vaizey CJ, Matzel K, Baeten C (2010) Sacral nerve stimulation for intractable constipation. Gut 59(3):333-340. https://doi.org/10. 1136/gut.2009.187989

27. Vaizey CJ, Carapeti E, Cahill JA, Kamm MA (1999) Prospective comparison of faecal incontinence grading systems. Gut 44(1): $77-80$

28. Dindo D, Demartines N, Clavien PA (2004) Classification of surgical complications: a new proposal with evaluation in a cohort of 6336 patients and results of a survey. Ann Surg 240(2):205-213

29. Chan DS, Delicata RJ (2016) Meta-analysis of antegrade continence enema in adults with faecal incontinence and constipation. Br J Surg 103(4):322-327. https://doi.org/10.1002/bjs.10051

30. Peeraully MR, Lopes J, Wright A, Davies BW, Stewart RJ, Singh SS, More BB (2014) Experience of the MACE procedure at a regional pediatric surgical unit: a 15 -year retrospective review. European Journal of Pediatric Surgery : official journal of Austrian Association of Pediatric Surgery [et al] = Zeitschrift fur Kinderchirurgie 24(1):113-116. https://doi.org/10.1055/s-00331357502

31. Marshall J, Hutson JM, Anticich N, Stanton MP (2001) Antegrade continence enemas in the treatment of slowtransit constipation. J Pediatr Surg 36(8):1227-1230. https:// doi.org/10.1053/jpsu.2001.25768

32. Yerkes EB, Cain MP, King S, Brei T, Kaefer M, Casale AJ, Rink RC (2003) The Malone antegrade continence enema procedure: quality of life and family perspective. J Urol 169(1):320-323. https://doi.org/10.1097/01.ju.0000041721.26576.92 
33. Altomare DF, Rinaldi M, Rubini D, Rubini G, Portincasa P, Vacca M, Artor NA, Romano G, Memeo V (2007) Long-term functional assessment of antegrade colonic enema for combined incontinence and constipation using a modified Marsh and Kiff technique. Dis Colon Rectum 50(7):1023-1031. https://doi.org/10.1007/s10350006-0863-0

34. Chereau N, Lefevre JH, Shields C, Chafai N, Lefrancois M, Tiret E, Parc Y (2011) Antegrade colonic enema for faecal incontinence in adults: long-term results of 75 patients.
Colorectal Disease : the official journal of the Association of Coloproctology of Great Britain and Ireland 13(8):e238e242. https://doi.org/10.1111/j.1463-1318.2011.02651.x

35. Yardley IE, Pauniaho SL, Baillie CT, Turnock RR, Coldicutt P, Lamont GL, Kenny SE (2009) After the honeymoon comes divorce: long-term use of the antegrade continence enema procedure. J Pediatr Surg 44(6):1274-1276; discussion 1276-1277. https://doi.org/10.1016/j.jpedsurg.2009.02.030 